\title{
FERRAMENTAS OFFLINE DE COMUNICAÇÃO: RESGATE DO DIÁLOGO COM A POPULAÇÃO RURAL
}

\author{
Marina Muniz Mendes ${ }^{1}$ \\ Magno Medeiros $^{2}$
}

\begin{abstract}
Resumo
O tema deste trabalho são as ferramentas de comunicação utilizadas em publicações voltadas para a população rural. O objetivo é analisar a forma de publicações que promovem diálogo com camponeses. Os comunicadores, que têm como stakeholders trabalhadores da agricultura familiar, fazem o uso de elementos visuais e textuais específicos para transformar informação em comunicação. É um estudo das cartilhas produzidas pelo Ministério do Desenvolvimento Agrário, focalizando o perfil dos trabalhadores rurais e a necessidade de uma assessoria de comunicação integrada. Os pequenos agricultores compõem o público interno ou externo de diversas organizações. Sendo assim, em pleno século $\mathrm{XXI}$, não devem cair em esquecimento os canais offline, principal forma de contato com esse grupo.
\end{abstract}

Palavras-chave: Assessoria de Comunicação; Campesinato; Comunicação Rural.

\section{OFFLINE COMMUNICATION TOOLS: RESCUE OF DIALOGUE WITH RURAL POPULATION}

\footnotetext{
${ }^{1}$ Graduada em Comunicação Social - Jornalismo (UFG). Especialização em Assessoria de Comunicação e Marketing (UFG). Especialização em Artes Visuais (Senac). Mestranda em Comunicação (UFG). E-mail: marinamunizmendes@gmail.com

${ }^{2}$ Graduado em Comunicação Social - Jornalismo (UFG). Mestrado em Ciências da Comunicação (USP). Doutorado em Comunicação e Educação (USP). Prof. Associado da Universidade Federal de Goiás (UFG). E-mail: magno.ufg@gmail.com
} 


\begin{abstract}
The theme of this work are the communication tools utilized in publications aimed the rural population. The goal is to analyze the form of publications which promote dialog with peasants. The communicators, who have as stakeholders workers from family agriculture, make use of specific visual and textual elements to transform information into communication. It is a study of the primers produced by the Ministry of Agrarian Development, focusing the profile of rural workers and the need for an integrated communication advisory office. The small agriculturalists constitute the internal or external public of several organizations. Thereby, in the XXI century, the offline channels must not be forgotten, being the principal form of contact with this group.
\end{abstract}

Key-words: Communication Advisory Office; Peasantry; Rural Communication.

\title{
1. INTRODUÇÃO
}

Cultura e comunicação caminham juntas. A comunicação é um dos elementos determinantes que faz a cultura existir e se modificar. A cultura está em constante produção e evolução, sendo um processo contínuo e mutável, tanto em seu sentido empírico quanto epistemológico. Nem tudo é cultura, mas ela é uma das constituições da prática social.

Apesar do processo da comunicação humana ser universal, a vivência faz com que a comunicação, bem como a cultura, fora dos grandes centros seja diferente da urbana; o pensar, sentir e agir são diferentes. As formas de comunicação dos habitantes do campo e da cidade se diferem. A cultura dos povos do campo é, eminentemente, oral, necessitando habilidade ao comunicador para produzir materiais impressos que transmitam a pessoalidade provocada pela oralidade.

Os meios visuais são indicados para a comunicação com a população camponesa devido ao seu poder de atração. Certos grupos sociais sustentam suas interpretações nas imagens, bem como na oralidade. Poucos anos de educação formal refletem em uma difícil compreensão da escrita. Da mesma forma, uma educação que destoa com a realidade camponesa dificulta a interpretação textual. 
Característica marcante do campesinato ${ }^{3}$ é o baixo nível de instrução. Dados do Instituto Brasileiro de Geografia Estatística (IBGE) ${ }^{4}$ revelam que, no Brasil rural, existem quatro milhões de analfabetos e $80 \%$ da população tem baixa escolaridade. $O$ quadro das escolas rurais também é crítico, são 76 mil escolas, 6,2 milhões de alunos matriculados e 342,8 mil professores, dos quais pouco mais da metade tem estudo superior ${ }^{5}$.

A população rural é composta por pessoas dos mais variados níveis de escolaridade, desde analfabetos até pósgraduados. Entretanto, pesquisas revelam que o perfil dos habitantes do campo consiste em pouco hábito de leitura, interpretação literal, curto período de atenção e não familiaridade com linguajar técnicocientífico.

A assessoria de comunicação utiliza informações visuais integradas, texto e imagens, para comunicar com a população camponesa sobre temáticas do mundo contemporâneo. A produção de materiais adequados é um desafio com o potencial de contribuir para um desenvolvimento rural.

A percepção e a linguagem habitual do profissional de comunicação e do camponês costuma ser diferente. É necessário a quem escreve e a quem lê uma sintonia, familiaridade com temas, meios e linguagem. A concepção de tempo é diferença marcante entre os habitantes da cidade e do campo. Para promover a comunicação, o comunicador precisa ser paciente:

O agricultor e sua família trabalham num certo ambiente formado pelo clima, a topografia do solo, a flora e a fauna (...). Além disto, para poder trabalhar o solo, o agricultor utiliza certas ferramentas e aplica certas técnicas. O fato de muitos destes fatores não serem controláveis pelo agricultor imprime à agricultura um caráter aleatório e exige dos que a exercem qualidades de paciência e serenidade. (BORDENAVE, 1992).

\footnotetext{
${ }^{3}$ A opção pela escolha de termo campesinato, ocorre por sua definição ser ampla. Camponeses podem ser agricultores, guardiões de sementes, extrativistas, quilombolas, fiandeiras, donas de casa ou outros que vivem e desempenhem atividades, predominantemente, ligadas ao campo. A definição não exclui crianças e idosos, ao contrário de trabalhador rural. Tampouco restringe sua atividade profissional como ocorre em agricultor ou lavrador.

${ }^{4}$ Censo Agropecuário 2006.

${ }^{5}$ Instituto Nacional de Estudos e Pesquisas Educacionais (Inep/Mec) 2010.
} 
Após a revolução industrial, o ritmo da cidade e do campo passou a ser diferente. Houve importantes avanços tecnológicos, dos meios de transporte, produção e comunicação, desencadeando um dia a dia urbano mais acelerado, frenético. O trabalhador das cidades adaptou às mudanças, mas houve pouco reflexo para a realidade camponesa.

O camponês segue lidando, diariamente, com o risco, a incerteza e moldando sua vida através do que o cerca, a natureza. O homem e a mulher do campo refletem sobre o sol, a lua, as árvores, os pássaros, a terra, a comunidade. $E$ os habitantes dos centros urbanos, há séculos, se distanciaram dessas influências.

Ler é um processo interpretativo. O sentido varia de acordo com os conhecimentos prévios, adquiridos na escola ou através de experiências. O conhecimento do homem do campo é gerado pela educação formal, mas sua principal fonte é cultural, repassado de geração em geração por meio da observação da natureza, das crenças, da tradição.

Deve ser feita a escolha adequada dos canais de comunicação e construção personalizada da mensagem para atingir a população do campo. É trabalho dos comunicadores, que lidam com esse público, mapear as características dos trabalhadores rurais, com objetivo de fazer com que a informação tenha capacidade interpretativa de ser transformada em comunicação.

Uma publicação guardada na gaveta é informação. A leitura e reflexão sobre o material faz com que a informação seja transformada em comunicação. Informação é o registro de dados, fatos, ideias ou estudos em algum suporte, podendo ser escrito, eletrônico, visual, de áudio ou qualquer outro formato. Já comunicação pressupõe capacidade de decodificação e interpretação da mensagem.

Informação, sem comunicação, não promove o desenvolvimento. Entre as décadas de 1960 e 1980 houve a intensificação de estudos sobre a adequação de conteúdo para o pequeno agricultor. Para discutir comunicação no campo, três conceitos são considerados estruturantes: informação agrícola (BORDENAVE, 1992), extensão (FREIRE, 1988) e comunicação rural (BORDENAVE, 1992).

O primeiro conceito trata-se de um intenso e concentrado uso de meios e mensagens buscando que determinado grupo adote um comportamento desejado. É uma difusão unilateral de informações, aliada a técnicas de marketing, utilizando-se de recursos da publicidade comercial para promover campanhas no meio rural, valendo-se de truques com apelo emocional e ameaças. 
O segundo pode ser compreendido como invasão cultural, ir ao encontro de minorias para normalizá-las de acordo com padrões estabelecidos pelo grupo dominante. Extensionistas invadem 0 espaço histórico-cultural das minorias para impor sistemas de valores, estimulando a massificação e manipulação. Fazendo dos povos do campo receptores de comunicados, negando a reflexão.

O último conceito vai à contramão dos demais. É multilateral, objetivando a construção de etapas de diálogo, comunicação, consciência crítica, aquisição de poder e autonomia decisória. A comunicação rural, renovada pelos princípios da comunicação popular e inserida no conceito de comunicação pública, busca superar a in-comunicação existente nas zonas rurais.

A comunicação pública, seja feita pelo governo, terceiro setor ou empresas privadas, ocorre na medida em que o cidadão começa a ter voz, pressionando instituições a se preocupar com questões da cidadania (DUARTE, 2009). Quando parcelas, antes marginalizadas, passam a ser encaradas como cidadãs, havendo preocupação na produção de materiais que objetivem a efetivação de direitos civis e políticos. "São as massas tornando-se socialmente visíveis" (BARBERO, 2003).

Desde 1995, com o advento da internet comercial no Brasil, a tendência é a intensificação da comunicação online. Entretanto, segundo o Centro Regional de Estudos para o Desenvolvimento da Sociedade ${ }^{6}$, apenas $15 \%$ domicílios rurais têm acesso à internet. A pesquisa não especifica o perfil dos domicílios, mas apreende-se que os empresários do agronegócio possam contribuir, significativamente, para esse número. Dentre os domicílios urbanos, $48 \%$ possuem acesso à Internet.

É inegável o poder comunicacional da rede mundial de computadores, mas ainda hoje são os canais tradicionais que permitem o diálogo com os camponeses. Fortalecer publicações offline, mesmo em pleno século XXI, significa não esquecer parcelas significativas da população brasileira.

Os povos do campo têm pouco acesso aos canais online. Além disso, as tradições comunicacionais das populações marginalizadas sobrevivem às inovações tecnológicas, demonstrando capacidade de resistência cultural, no tempo e no espaço (MELO, 2008). O folclore é um dos grandes canais de

\footnotetext{
${ }^{6}$ Pesquisa TIC Domicílios 2013, divulgada em junho de 2014, e realizada pelo Centro Regional de Estudos para o Desenvolvimento da Sociedade da Informação sob assistência da Unesco (Cetic.br), do Núcleo de Informação e Coordenação do Ponto BR (NIC.br).
} 
comunicação coletiva e suas manifestações são inerentes à vida dos povos do campo:

Todos os países do mundo, raças, grupos humanos, famílias, classes profissionais possuem um patrimônio de tradições que se transmite oralmente e é defendido e conservado pelo costume. Esse patrimônio é milenar e contemporâneo. Cresce com os conhecimentos diários desde que se integram nos hábitos grupais, domésticos ou nacionais. Esse patrimônio é o folclore. (MELO, 2008).

As classes marginalizadas, sejam urbanas ou rurais, utilizam aspectos folclóricos para estabelecer comunicação entre si e também com 0 exterior. A partir dessa constatação, os comunicadores perceberam o poder da tradução de conteúdos midiáticos, utilizando aspectos relacionados às manifestações folclóricas.

\section{MÉTODOS}

A intenção deste artigo é analisar ferramentas comunicacionais que estão dando resultados positivos no diálogo com a população camponesa. São raros os estudos atuais sobre publicações voltadas às populações que vivem fora dos centros urbanos, que seguem offline, e fazem uma ponte com o trabalho das assessorias de comunicação.

O corpus de pesquisa compreende duas edições de publicações produzidas pelo Ministério do Desenvolvimento Agrário (MDA), tendo como público alvo pequenos produtores. Foram estudadas as cartilhas: Programa nacional de produção e uso de biodiesel: inclusão social e desenvolvimento territorial; e Orgânicos na alimentação escolar: a agricultura familiar alimentando o saber.

A escolha das publicações foi realizada através da amostragem estatística aleatória simples, utilizando a técnica da representatividade. $\mathrm{O}$ método de análise é indutivo. A pesquisa é descritiva, qualitativa e documental, de análise da comunicação visual de publicações oficiais, ou seja, da forma, não atentando ao conteúdo. 
A escolha do corpus leva em consideração que o MDA tem entre suas competências "promoção do desenvolvimento sustentável do segmento rural constituído pelos agricultores familiares" 7 . A respeito da comunicação, cabe ao gabinete funções de: ocupar-se das relações públicas, providenciar a publicação oficial, divulgação de matérias relacionadas com a área de atuação do ministério, planejar, coordenar e supervisionar o desenvolvimento das atividades de comunicação social.

\section{RESULTADOS E DISCUSSÕES}

O material produzido pelo MDA influencia demais publicações voltadas aos pequenos agricultores, sejam produzidas por demais órgãos governamentais, movimentos sociais ou empresas privadas. O ministério faz uso tanto de canais de comunicação online quanto offline. Online destacam-se o site, facebook, flickr e twitter. Entretanto, os principais canais de comunicação rural seguem offline, através de visitas in loco, oficinas, reuniões, palestras, seminários ou por meio de boletins, cartazes, cartilhas e outros impressos.

Uma das principais representações da folkcomunicação, em meio impresso, são as cartilhas. Trata-se de material de fácil leitura e finalidade pedagógica. Para a produção de cartilhas são inseridas informações visuais integradas, texto e imagem, para comunicar com os camponeses sobre temáticas do mundo rural contemporâneo.

A linguagem do povo segue tendência própria e é diferenciada da utilizada pelas classes oficiais e dirigentes (BELTRÃO, 2001). Por sua vez, a comunicação oficial que traz resultados positivos faz o uso de características folclóricas para promover a comunicação com grupos populares. É a chamada folkcomunicação (BELTRÃO, 2001).

Os registros gráficos aparecem de forma articulada, interligando texto e ilustração. Há imagens em quase metade (46\%) das páginas da primeira cartilha e em todas as páginas da segunda. Totalizando $73 \%$ de páginas com imagens. A tônica da cartilha sobre biodiesel é a complementação ilustrativa do texto com fotos, a sobre orgânicos é com ilustrações.

Não há fórmula para a construção imagética das publicações. Cada temática define o recurso visual mais utilizado, podendo ser fotos, ilustrações ou gráficos. Apesar disso, as

${ }^{7}$ Estrutura regimental do Ministério do Desenvolvimento Agrário. 
publicações seguem um mesmo perfil. Todas as páginas do material são coloridas, como forma de atrair a atenção do leitor e facilitar a visualização das imagens.

O leitor, camponês, consegue se identificar com as fotografias. A intenção é que as fotos capturem um instante da realidade da vida no campo. Alguns olham para a câmera, outros não. As fotos revelam agricultores realizando atividades do dia a dia, quase sempre alguma ação, transmitindo a ideia de movimento, trabalho.
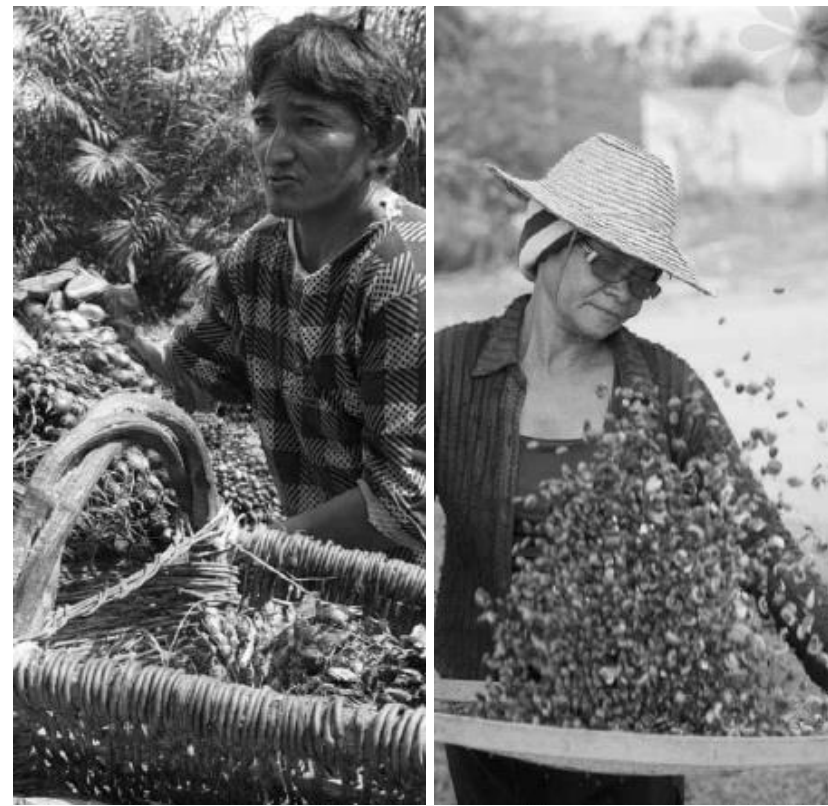

Figura 1 - Fotografias de camponeses contidas na cartilha "Programa nacional de produção e uso de biodiesel"

Como observado na figura 1 , as fotografias apresentam homens e mulheres de diferentes idades, realizando atividades múltiplas, simbolizando a pluralidade existente no campo. Promovendo também o reconhecimento do leitor com o agricultor ou agricultora da imagem. São capturados também elementos presentes na vida no campo, como o chapéu de palha, roupas sóbrias e instrumentos de trabalho. 
A in-comunicação pode ocorrer pelo isolamento geográfico, entretanto sua principal causa é social, determinada pelo analfabetismo, baixo nível de instrução, necessidade de trabalhar longas horas ou pela diferença de status entre os patrões e os trabalhadores (BORDENAVE, 1992). A intenção é diminuir a distância, segundo a definição sociológica, como "a que resulta da diversidade de posições sociais dos indivíduos ou grupos em suas relações (de superioridade ou de inferioridade) com outros indivíduos ou grupos" 8 . Ao apresentar fotografias de camponeses reais, realizando atividades corriqueiras, a in-comunicação é afastada.

Os camponeses representados são semelhantes ao leitor, seja culturalmente ou socialmente. Não há diferença de status ou incompatibilidade com a realidade rural. As fotos são esteticamente bonitas e bem produzidas, representando pessoas simples, mas longe da ridicularização. Os sujeitos não são maltrapilhos ou têm aparência desalinhada.

Ao referir às pessoas que vivem nessas áreas opostas, uma problemática pode ser revelada. Em urbano, o dicionário ${ }^{9}$ define 0 habitante da cidade como "civilizado, polido, cortês, afável", trazendo a oposição ao habitante rural, definindo-o como "descortês, rústico".

Não é feito o uso de efeitos especiais, o tratamento das imagens é apenas para fazer pequenos ajustes, como a inserção da logomarca de programas. A intenção é fazer com que a captura da imagem seja a mais próxima possível do olho humano. Há também o uso de lente close-up em elementos da natureza, com finalidade estética, fazendo o rodapé das páginas.
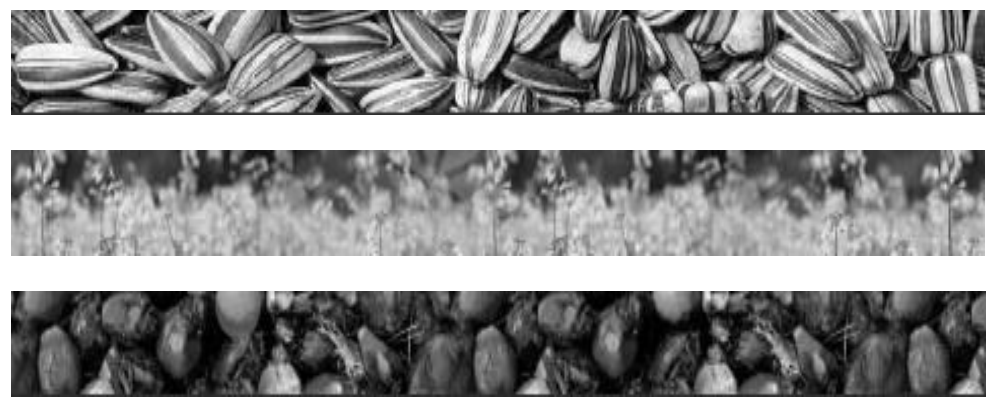

Figura 2 - Fotografias de elementos da natureza contidas na cartilha "Programa nacional de produção e uso de biodiesel"

\footnotetext{
${ }^{8}$ Definição do dicionário Michaelis 2009

${ }^{9}$ Definição do dicionário Michaelis 2009.
} 
Como observado na figura 2, o camponês lida quase, diariamente, com sementes, plantas e flores. As fotografias são informações que podem ser, facilmente, interpretadas pelos camponeses e transformadas em comunicação, pois se referem a ações ou elementos que compõem o dia a dia na zona rural, que fazem parte do conhecimento prévio.

As ilustrações contêm aspectos caricaturais, mas sem se afastar da realidade rural. São imagens, em série, reproduzindo estórias de homens e mulheres do campo, com a inclusão de objetos, instrumentos de trabalho e produtos familiares aos camponeses, como mostra o exemplo.
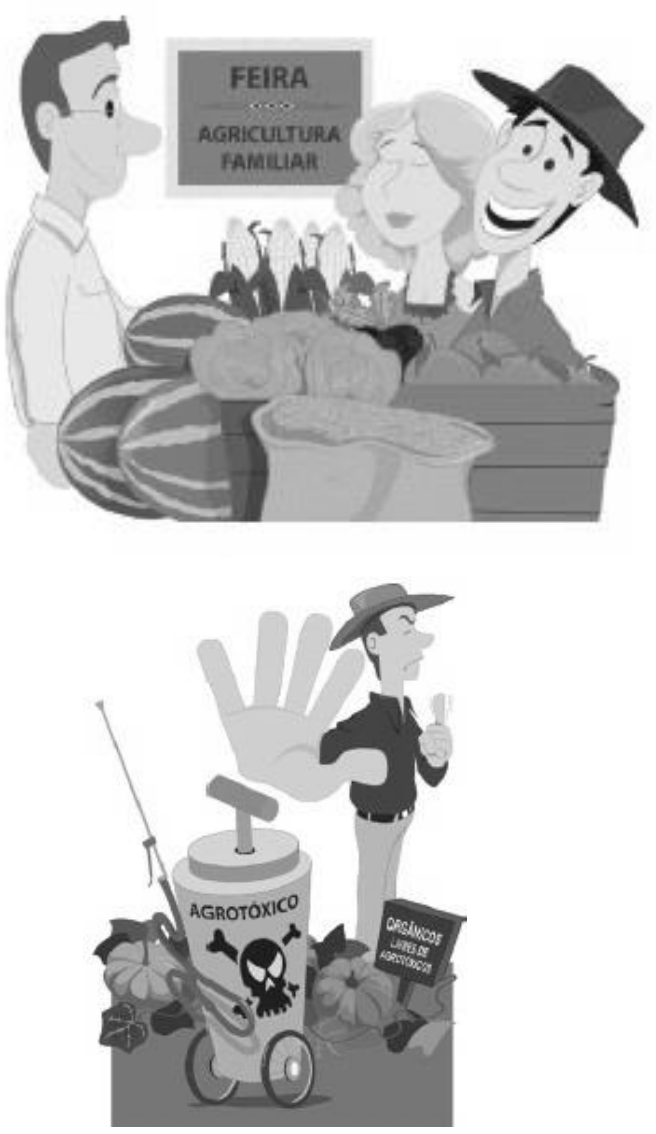


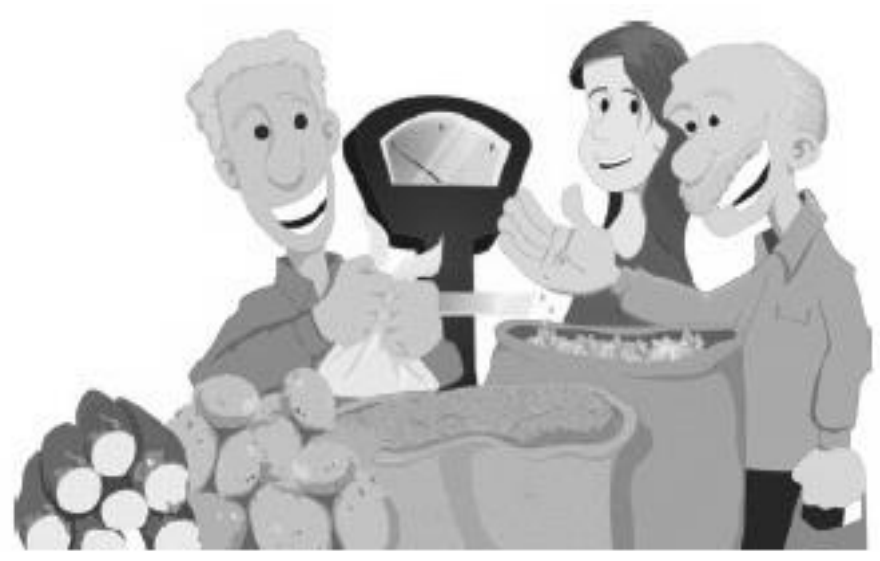

Figura 3 - Ilustrações retiradas da cartilha "Orgânicos na alimentação escolar"

Como observado na figura 3, nas feiras livres a balança utilizada é do modelo antigo, por exemplo. Isso é familiar aos trabalhadores rurais. Bem como o aplicador de agrotóxico, os produtos camponeses ou os sacos para guardar sementes. A tônica é a adoção de formas comunicacionais compreensíveis aos agricultores:

É proverbial a acuidade com que o homem criado perto da natureza percebe e interpreta os sinais visuais e auditivos típicos de seu ambiente: formas de nuvens, pisadas de animais, cor das folhas, barulho do vento e das águas, tudo fala ao homem do campo, que distingue detalhes que escapam à percepção do homem urbano. (BORDENAVE, 1992).

Os camponeses dominam a interpretação da natureza, cabendo ao comunicador a representação desses elementos nos textos e imagens. O homem do campo está acostumado a lidar com o concreto, interpretando, literalmente, as ilustrações. O sentido figurado deve ser evitado, pois a prevalência é pelo entendimento do sentido denotativo e não conotativo.

Caricaturar excessivamente é um erro comum. Humanizar objetos, plantas ou animais confunde o leitor, que não enxerga na 
realidade tal personificação. Também se deve preocupar com a quantidade de detalhes. Detalhamento em excesso ou a falta dele faz com que a compreensão diminua.

O folclórico está na representação dos costumes tradicionais, indumentárias, arte e festas. A ilustração de feiras camponesas é frequente, sendo um grande representante do folclore camponês. As feiras são locais de troca e venda de produtos, sendo realizadas, no Brasil, há séculos.

As feiras são geridas pelos próprios camponeses, sendo local não só de comercialização de alimentos ou produtos. É o momento de encontro com a comunidade e de contato com o urbano. Um ambiente de reconhecimento e de difusão da cultura dos povos do campo

O chapéu é o grande representante da indumentária do trabalhador rural, sendo também elemento folclórico. O chapéu não é utilizado apenas como proteção contra o sol, faz parte da identidade. É um hábito transmitido de geração em geração, oralmente ou por imitação, com nenhuma influência da educação formal.

Sobre a formatação, não há entrada de parágrafo, é utilizado apenas espaçamento de parágrafo, chamando mais atenção ao texto que aos espaços em branco. Os textos são organizados em única coluna por página, na forma de tópicos, com uso recorrente de interrogações e exclamações, como evidenciam os seguintes exemplos. 


\section{Agora é Lei! Alimentação escolar é com a agricultura familiar}

É por causa da preocupação com a segurança alimentar entre os alunos das escolas públicas que, recentemente, foi aprovada a Lei da Alimentação Escolar ( $n=11.947 / 2009$ ). Feita com base nos conceitos de segurança alimentar e nutricional, a nova Lei determina que $30 \%$ dos recursos repassados pelo FNDE para a alimentaçäo escolar sejam aplicados na compra de produtos da agricultura familiar (também do empreendedor familiar rural ou de suas organizações, priorizando os assentamentos de reforma agrária, as comunidades tradicionais indígenas e comunidades quilombolas).

\section{HÁBITOS ALIMENTARES \\ SEGURANÇA ALIMENTAR \\ Quando 0 assunto \\ é alimentacão escolar, o PNAE cuída só dos recursos?}

Claro que não! Afinal, um dos objetivos do programa é a promoção de hábitos alimentares saudáveis, que incluem alimentação saudável e segura e o respeito à cultura e às tradições de cada região.

Figura 4 - Exemplos de títulos extraídos da cartilha "Orgânicos na alimentação escolar".

Como observado na figura 4 , os títulos devem ser claros e diretos. A leitura tem que ser compreendida como uma conversa entre o emissor e o leitor. Uma construção simples, sem rodeios, que passe a sensação de oralidade. É feito o uso corrente da estrutura 
narrativa, mais facilmente assimilável pelo leitor. A maioria dos títulos usa a forma direta: sujeito, verbo, complemento.

As frases e os parágrafos são curtos. Quanto maior o número de palavras, menor a inteligibilidade. Nas publicações, o fundo é predominantemente branco, texto em preto e cores nos títulos. Os materiais são escritos em linguagem acessível. Também ocorrem repetições de ideias ao longo dos parágrafos, com pequenas variações, para facilitar a fixação do conteúdo. As publicações destacam o mais importante, em negrito ou em cores. Ler o que está destacado é acompanhar um resumo.

O trabalho do camponês é concreto, com um plano definido. Há o período correto de ordenhar, plantar, podar e colher. As publicações são objetivas. "Quem está acostumado a apalpar o que produz gosta de ler coisas concretas, sem rodeios. Palpáveis" (GIANNOTTI, 1998). As publicações analisadas contam com poucos elementos que dificultam a leitura, como aspas, gerúndios e parênteses.

Nas cartilhas, o camponês é tratado de forma personalizada e informal. Há o emprego constante do pronome você. "Aqui você fica sabendo de tudo"; "Se você é agricultor familiar", são alguns exemplos. O sujeito não é indeterminado. A mensagem é direcionada ao leitor, para que ele adquira determinado conhecimento e o transforme em ação.

O desenvolvimento rural gira em torno da comunicação, visto que os agricultores necessitam dela para tomar suas decisões de produção e de convivência (BORDENAVE, 1992). O pronome nós é recorrente e visa a inclusão do emissor na missão de promover o desenvolvimento rural, como nos exemplos: "A tarefa parece difícil quando estamos sozinhos", "Quando consumimos alimentos que são produzidos ali mesmo onde vivemos", "Todos podemos fazer parte".

Não é o emissor que está sendo integrado na tarefa. É o receptor que passou ser considerado um ator para o desenvolvimento rural. A comunicação é resultado do poder de cidadania dos povos do campo, adquirido após anos de luta por reconhecimento. Comunicação é a manifestação política mais importante da organização da sociedade contemporânea (DUARTE, 2009).

As cartilhas analisadas são atemporais, não apresentando sequer 0 ano de publicação. Elas não se prendem ao factual, podendo ser lidas ou estudadas por longos períodos de tempo e ainda se fazerem atuais, atendendo as características do público alvo e da dificuldade de distribuição periódica dos materiais.

O número de páginas também é variado, mas segue a 
lógica de que o material será utilizado por muito tempo e também tem finalidade pedagógica, sendo assim as informações devem ser as mais completas possíveis. Ademais, a grande quantidade de fotos e ilustrações aumenta o volume de informação. "Programa nacional de produção e uso de biodiesel" e "Orgânicos na alimentação escolar" possuem, respectivamente, 48 e 23 páginas.

A aparência não tem função apenas decorativa. Ela é utilizada também para facilitar o manuseio e leitura dos materiais, sendo fundamental para o sucesso de publicações para a área rural. A forma é tão importante quanto o conteúdo, visto que o primeiro impacto pode atrair ou desencorajar a leitura.

A linguagem camponesa é o conjunto de palavras, frases, imagens e estilos apropriados à comunicação rural. É todo um repertório, que para ser articulado, deve contar com profissionais de comunicação integrados, para que haja um planejamento global da forma das publicações, bem como de seu conteúdo. As características, estratégias e objetivos das publicações devem ser claros.

Há uma equipe de comunicação para desenvolver tais publicações. O expediente é composto por: coordenador de comunicação social; coordenador de jornalismo da assessoria de comunicação; chefe de assessoria de comunicação; edição e direção de criação; design gráfico e infográfico; fotos; colaboradores. A eficiência existe porque há uma equipe integrada para a produção de publicações, como destaca:

As organizações devem ter entre os objetivos de comunicação o de buscar o equilíbrio entre os seus interesses e os dos públicos a elas vinculados. Esses objetivos só serão alcançados se a comunicação for planejada de forma estratégica, utilizando técnicas de relacionamentos e meios específicos, devidamente selecionados, e integrando todas as atividades comunicacionais, dentro de uma filosofia de comunicação organizacional integrada. (KUNSCH, 2003).

A intenção é permitir o estabelecimento de uma política global, com maior coerência entre os diversos programas comunicacionais, bem como uma linguagem comum entre os materiais. Tais fatores são observados nas publicações analisadas. Trata-se de uma gestão coordenada e sinérgica dos esforços humanos e organizacionais, visando a eficácia (KUNSCH, 2003). 


\section{CONSIDERAÇÕES FINAIS}

A assessoria de comunicação deve ser capaz de transitar entre espaços e públicos diferentes por meio da adequação na linguagem e escolha correta dos meios de comunicação. Para a produção de publicações para trabalhadores da agricultura familiar, a equipe de comunicação deve mapear o perfil desse público:

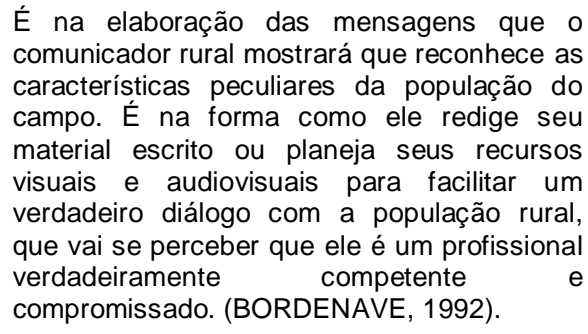

Trabalhar com povos do campo é um resgate aos princípios da comunicação social, garantindo o direito à informação através de uma dedicação com a realidade objetiva, informando de maneira ética. O meio de comunicação, bem como a forma de apresentação, é valor determinante para o contato com camponeses. Por isso, o comunicador deve também ser criativo para chamar à atenção dos camponeses.

As mensagens devem ser construídas em linguagem acessível e os meios utilizados para se comunicar devem ser de fácil leitura, manuseio e acesso. Afinal, acima de mercadoria, informação é um bem social. A comunicação integrada permite uma adequação mais eficiente da forma, conteúdo e demais ferramentas comunicacionais.

É necessária a união de profissionais capacitados para articular ideias, textos, imagens, identidade. A atuação de um único profissional ou uma equipe não interdisciplinar é inviável. Profissionais de jornalismo, relações públicas e publicidade e propaganda, trabalhando em conjunto, produzem materiais mais adequados para as demandas do campo.

Os comunicadores se defrontam com grupos sociais que possuem manifestações singulares, necessitando de uma equipe integrada para buscar sintonia com as formas de comunicação desses grupos. Os comunicadores fazem a ponte entre os 
camponeses e os componentes da política agrária da nação ou viceversa.

O MDA possui uma assessoria de comunicação integrada, o que potencializa o sucesso do diálogo com os camponeses. As cartilhas são bem produzidas, de fácil leitura, repletas de imagens e com tiragem direcionada às áreas rurais. Há um caráter de profissionalismo na produção das publicações.

A atenção à produção de cartilhas deve ser redobrada para não fechar os canais de diálogo. Deve-se profissionalizar o trabalho de comunicação com os camponeses e ir à contramão da infantilidade dos materiais, visto que "o popular sempre se identifica secretamente com o infantil, com o ingênuo, com aquilo que é cultural e politicamente imaturo" (BARBERO, 2003).

É fato que o nível de instrução no campo costuma ser menor que na cidade. Mas, isso não significa que os camponeses tenham capacidade intelectual inferior. É uma classe de trabalhadores e trabalhadoras que repassam suas experiências de vida, oralmente, há séculos. A bagagem cultural é vasta e o conhecimento também.

Os povos do campo articulam suas ideias de maneira diferente dos habitantes das cidades. Para tanto, é necessário pensar em métodos para superar a dificuldade de comunicação entre o comunicador e o camponês. A utilização de textos e imagens integrados, bem como de material que passa a ideia da oralidade são ferramentas que abrem a possibilidade do diálogo.

"E de que serve um livro sem figuras nem diálogos?" (CARROLL, 2010), pensa Alice ${ }^{10}$ sobre uma publicação que sua irmã lia. A ficção ilustra a realidade. Imagens e oralidade são as ferramentas comunicacionais preferidas pelas camadas populares. Elas chamam a atenção, são atraentes, e têm boa capacidade de interpretação.

Durante um longo período não ocorreu a comunicação com os povos do campo. Os serviços de extensão rural promoveram invasões culturais e o despejo frenético de informações, repelindo a comunicação. As cartilhas analisadas revelam a atual reação aos projetos de extensão.

O modelo que está se mostrando viável é o que parte do respeito aos povos, considera a convivência e a diversidade cultural. É uma comunicação que revela o campo para o camponês, apresentando suas diversas cores, idades, gostos e características.

10 Protagonista do livro Alice no País das Maravilhas, clássico da literatura infantojuvenil. 
O trabalhador rural não se vê como um Jeca Tatu ${ }^{11}$, para tanto não se deve representá-lo como tal.

A população rural é composta por 30 milhões de brasileiros $^{12}$, cerca de $16 \%$ da população do país. São homens, mulheres, crianças e idosos com as mais variadas características físicas ou culturais. O povo do campo deve se reconhecer nas publicações, sendo necessário incluir essa diversidade e não limitar através da representação do homem pardo com cerca de 30 anos.

O comunicador também deve ter atenção na utilização de ferramentas digitais, tônica do século XXI. Apoiar-se no online é um campo seguro. Os custos são baixos, os profissionais cada vez mais antenados à convergência digital, com possibilidade de grande e imediata repercussão.

Em contrapartida, camponeses, assim como diversos outros grupos e classes, estão à margem da possibilidade de acesso digital. Apenas um número restrito de agricultores tem acesso à internet em domicílio. Também são poucos os que sabem utilizar o computador. Sobre o frenesi em torno do online apreende-se que:

Recontextualização da cultura que nos confronta com essa outra experiência cultural que é a popular, em sua existência múltipla e ativa não apenas na memória do passado, mas também conflitiva e na criatividade atuais. Pensar os processos de comunicação neste sentido, a partir da cultura, significa deixar de pensá-los a partir das disciplinas e dos meios. Significa romper com a segurança proporcionada pela redução da problemática da comunicação à das tecnologias. (BARBERO, 2003).

Reduzir a comunicação às tecnologias é negar a cultura popular. A comunicação das massas segue alicerçada nos costumes tradicionais, crenças, superstições, cantos, lendas, ou seja, em manifestações existentes há séculos e até milênios. Essa é maneira de se expressar dos povos do campo.

"Com o advento da tecnologia elétrica, o homem prolongou, ou projetou para fora de si mesmo, um modelo vivo do próprio sistema nervoso central" (MCLUHAN, 1971). A internet impulsiona

\footnotetext{
11 Personagem criado por Monteiro Lobato na obra Urupês, publicada em 1918. Jeca Tatu era um caipira ignorante, doente, pobre, desassistido pelo poder público e que não gostava de usar sapatos.

${ }^{12}$ Censo Agropecuário 2006.
} 
ainda mais esse fenômeno de necessidade de um suporte que faz às vezes do nosso sistema nervoso. Sendo assim, o computador não é mero eletrodoméstico, suas significações vão muito além de um aparelho elétrico de uso caseiro.

$\mathrm{Na}$ internet, assim como ocorre com a televisão, "o meio é a mensagem (MCLUHAN, 1971)". Entretanto, os trabalhadores rurais, no geral, não possuem computador e pouco dominam a internet, considerando sim o computador como um eletrodoméstico no mesmo patamar da geladeira ou do aparelho de som.

Caso as informações não sejam repassadas, o contato não seja possível e a maneira de enviar a mensagem seja incompreensível, o processo é inútil. Não há comunicação. Produzir materiais com todas as preocupações apuradas neste artigo requer muito trabalho. É difícil, extenuante, mas a recompensa é uma publicação que será lida e interpretada do início ao fim. O prêmio é resgatar a comunicação social.

O desenvolvimento de novas tecnologias não alterou o trabalho rural da mesma forma que alterou o urbano. Trator, roda de fiar, fornalha de farinha, ralador e fogão a lenha são tecnologias aplicadas ao campo, mas tais exemplos não estão inseridos na concepção de novas tecnologias, baseada na comunicação em redes. O surgimento da Internet atribuiu à comunicação e ao trabalho a tônica online, mas isso ocorre fortemente nos grandes centros urbanos, não tendo o mesmo reflexo no interior do país. Isso, naturalmente, traz implicações e distanciamento entre o rural e o urbano.

\section{REFERÊNCIAS BIBLIOGRÁFICAS}

BARBERO, J. M. Dos meios às mediações: comunicação, cultura e hegemonia. Rio de Janeiro: UFRJ, 2003.

BELTRÃO, L. Folkcomunicação: um estudo dos agentes e dos meios populares de informação de fatos e de expressão de ideias. Porto Alegre: EdiPucRS, 2001.

BORDENAVE, J. D. 0 que é comunicação rural. São Paulo: Brasiliense, 1992.

CARROL, L. Alice no país das maravilhas. Porto Alegre: L\&PM, 2010. 
DUARTE, J. Comunicação pública: estado, mercado, sociedade e interesse público. São Paulo: Atlas, 2009.

FREIRE, P. Extensão ou comunicação? Rio de Janeiro: Paz e Terra, 1988.

GIANNOTTI, Vito. O que é jornalismo sindical. São Paulo: Brasiliense, 1998.

$\mathrm{KUNSCH}$, M. M. K. Planejamento de relações públicas na comunicação integrada. São Paulo: Summus, 2003.

MCLUHAN, M. Os meios de comunicação como extensões do homem. São Paulo: Cultrix,1971.

MELO, J. M. Mídia e cultura popular: história, taxionomia e metodologia da folkcomunicação. São Paulo: Paulus, 2008. 